\title{
Vocational identity and career progress: The intervening variables of career calling and willingness to compromise
}

\author{
Peter A. Creed, Melisa Kaya, and Michelle Hood \\ School of Applied Psychology \\ Griffith University, Australia
}

\section{Cite as:}

Creed, P. A., Kaya, M., \& Hood, M. (2018). Vocational identity and career progress: The intervening variables of career Calling and willingness to compromise. Journal of Career Development. doi:10.1177/0894845318794902

\begin{abstract}
Few studies have assessed potential underlying mechanisms related to vocational identity development. Informed by goal-setting and self-regulatory theories, this study $(N=286$ young adults; mean age $=20.5$ years) tested the relationship between vocational identity and career goal-performance discrepancy (i.e., the appraisal that unsatisfactory progress is being made in one's career), and assessed the process roles of willingness/unwillingness to compromise (as mediator) and career calling (as moderator) in this relationship. As expected, we found that a stronger vocational identity was associated with less willingness to compromise and fewer perceptions of career-related discrepancy, and that willingness to compromise partially mediated the relationship between vocational identity and career goalperformance discrepancy. Additionally, career calling strengthened the negative relationship (i.e., moderated) between vocational identity and willingness to compromise, and strengthened the negative relationship (i.e., moderated the mediation effect) between vocational identity and career goal-performance discrepancy.
\end{abstract}

Keywords: vocational identity; goal-performance discrepancy; willingness to compromise; career calling; defending behaviours; goal importance 
In $21^{\text {st }}$ Century advanced economies, the development of a healthy vocational identity is critically important for young people. Vocational identity underpins decisions around setting and progressing occupational directions, facilitates transitions from education/training to participation in the adult labour force, and sets the scene for later success and happiness (Murphy, Blustein, Bohlig, \& Platt, 2010; Porfeli, Lee, Vondracek, \& Weigold, 2011). A healthy vocational identity implies that young people understand their own vocational interests and life priorities and are engaged in managing a career direction (Holland, Daiger, \& Power, 1980). In essence, vocational identity reflects confidence and personal agency in the career domain (Hirschi, 2011). In this study, we tested this underlying assumption regarding career-related agency by examining the relationship between vocational identity and two agentic variables: willingness to compromise (i.e., preparedness to give up on desirable career goals) and career goal-performance discrepancy (i.e., perceptions that insufficient progress is being made to meet career goals). We also assessed whether willingness/unwillingness to compromise explains (i.e., mediates) the relationship between vocational identity and career goal-performance discrepancy, and whether career calling influences this mediated relationship between vocational identity career goal-performance discrepancy via willingness to compromise (i.e., moderated mediation). See Figure 1.

\section{Vocational Identity}

Vocational identity is defined as possessing "a clear and stable picture of one's goals, interests, and talents" (Holland, Gottfredson, \& Power, 1980, p. 1191). It is reflected in the development of important, age-appropriate competencies related to career exploration, decision-making, goal-setting, planning, goal-monitoring, and goal-management, and underpins motivation to set and strive for personally suitable and desirable, career-related goals (Hirschi, 2012; Guichard, Pouyaud, de Calan, \& Dumora, 2012). Numerous theories have been used to explain the development of vocational identity, including theories of 
circumscription and compromise (Gottfredson, 2005), person-environmental fit (Holland, Magoon, \& Spokane, 1981), career construction (Savickas, 2005), identity control (Burke, 1991; Kerpelman, Pittman, \& Lamke, 1997), and social cognitive career theory (Lent 2005). All of these theories are consistent with general, personal agency theories (aka goal setting and self-regulation theories; e.g., Bandura, 1991; Carver \& Scheier, 1990; Lord, Diefendorff, Schmidt, \& Hall, 2010), which state that individuals set goals (and standards) for themselves, implement strategies to meet these goals, and seek and respond to environmental feedback regarding progress to adjust their goals and/or strategies.

In the context of goal selection and management, because young people have limited personal and support resources, and there are many career options open to them, they must be selective in the goals they choose and optimise their efforts when chasing them. Goals that are achievable, reflect core interests, and are broadly consistent with the wishes of others (e.g., family) are likely to be most adaptive, and optimising time and energy commitments that target the achievement of those goals is likely to be most productive. Notwithstanding this, when goal progress and achievement are threatened, individuals will seek compensatory strategies to manage the threat (e.g., adjust the goal or effort expended; cf. selectionoptimisation-compensation, or SOC model; Baltes, 1997).

\section{Goal-Performance Discrepancy}

The key to managing career goal progress is the appraisal of career goal-performance discrepancies (Hu, Hood, \& Creed, 2016). In the process of deciding upon a career direction and developing and utilising skills and competencies that will advance this direction, young people encounter barriers and setbacks, which leads them to modify their career behaviours and career goals (Creed \& Gagliardi, 2014). In personal agency theories, the individual becomes aware of barriers and setbacks through feedback from the environment and selfreflection that a particular goal might not be suitable or achievable given the individual's 
current situation, resources, and effort. In turn, the appraisal of barriers stimulates a goalperformance discrepancy in the individual. A goal-performance discrepancy refers to an identified discrepancy between some set goal or internal standard and the progress being made towards that goal or the meeting of the standard.

When there is a negative goal-performance discrepancy (i.e., insufficient or no progress is being made), external feedback or internal reflection generates an uncomfortable state (e.g., dissatisfaction, unease, distress), which stimulates self-regulatory actions that are aimed at modifying the goal (e.g., lowering it), modifying behaviours (e.g., expending more effort), or doing both (e.g., working harder at a less demanding goal) to reduce the uncomfortable feelings (Lord et al., 2010). Goal-performance discrepancies can also be positive (e.g., progress is ahead of what is required to meet the goal or standard), in which case the individual will experience satisfaction and implement strategies such as raising the goal and/or easing back on effort (Bandura, 1991, 2001). However, individuals are more likely to remember negative rather than positive feedback (Green, Sedikides, Pinter, \& Van Tongeren, 2009), and a negative goal-performance discrepancy is disproportionately more influential on goal adjustment and behaviour change than a positive discrepancy (Wang \& Mukhopadhyay, 2012). Thus, we focus on negative goal-performance discrepancies, which is consistent with other studies in this area (e.g., Anderson \& Mounts, 2012; Donovan \& Williams, 2003; Tsaousides \& Jome, 2008).

\section{Vocational Identity and Goal-Performance Discrepancy}

Young people with a strong vocational identity can be considered to have developed attitudes and competencies needed to set and pursue career-related goals and to deal with barriers and setbacks as they occur. This should mean that they will perceive fewer barriers to their career direction, and, thus, perceive fewer career goal-performance discrepancies, as goal-performance discrepancies are triggered by feedback and perceptions of barriers. On the 
other hand, young people who do not have a robust vocational identity are at a greater risk of perceiving more threats and goal-performance discrepancies. Consistent with this, vocational identity is associated with a more optimistic outlook (Shin \& Kelly, 2013), fewer selfdefeating strategies, less career indecision (Sweeney \& Schill, 1998), and perceiving fewer career-related barriers (Downing \& Nauta, 2010; Gushue, Clarke, Pantzer, \& Scanlan, 2006). Thus, consistent with theory and empirical research, we expected (Hypothesis 1) that a stronger vocational identity would be associated with fewer negative career goal-performance discrepancies.

\section{Willingness to Compromise}

Career compromise can be considered as settling for a less-than-ideal career option (Creed \& Gagliardi, 2014), while willingness/unwillingness to compromise refers to the individual's preparedness to accept such a downgrade (Wee, 2013). As young people develop, think about, and make decisions regarding their career direction and future, many career-related compromises have to be made. These compromises, which are driven by perceptions of external barriers (e.g., availability of courses) as well as by internal reflection (e.g., realisation of amount of effort required), stem from acknowledging goal-performance discrepancies. Career compromise and goal adjustment are self-regulatory processes that fine tune or reset directions and effort (Lord et al., 2010), or in the SOC context, reflect compensatory actions to manage the threat (Baltes, 1997).

Decisions generally have been conceptualised as ranging from outcomes that are "good enough" (i.e., decisions that satisfy) to those that represent "best outcomes" for the individual (i.e., decisions that maximise benefits; cf. Simon, 1955). Compared to making decisions that satisfy, decisions that maximise require more time, effort, and consideration and are more likely to involve active coping strategies (Schwartz, Ward, Monterosso, Lyubomirsky, White, \& Lehman, 2002). Consistent with this, decisions that maximise, for example, lead to more 
successful career outcomes (Iyengar, Wells, \& Schwartz, 2006), generate more commitment to the goal on the part of the decision-maker (Sparks, Ehrlinger, \& Eibach, 2012), and are less likely to involve compromise (Wee, 2013). As individuals with "a clear and stable picture of [their] goals, interests, and talents" - that is, a more well-developed vocational identity (Holland et al., 1980, p. 1191) are in a better position to, and more likely to want to, maximise their outcomes than those with a less well-developed identity, they will put more time and energy into their decisions, and will be less likely to compromise on them. Thus, we expected (Hypothesis 2) that vocational identity would be associated negatively with a willingness to compromise (i.e., higher identity related to less willingness).

From a theoretical perspective, resisting compromise belongs to a set of defending or selfprotecting behaviours that the individual uses to maintain consistency between set goals/standards and discordant information from the environment and the individual's own self-doubts (Alicke \& Sedikides, 2009; Cramer, 2000; Heppner \& Kernis, 2011). These strategies are necessary for healthy functioning (Heppner \& Kernis, 2011; Taylor \& Brown, 1988) and are applied universally to protect the individual's identity (Gregg, Sedikides, \& Gebauer, 2011). For example, the need for compromise (and, thus, the acknowledgement or perception of goal-performance discrepancies) can be averted or diminished by discounting or denying negative feedback and seeking self-confirming feedback (Caudroit, Stephan, Brewer, \& Le Scanff, 2010; Kerpelman et al., 1997). As the primary purpose of defending behaviours is to limit discrepancies between self-set goals/standards and goals/standards defined by negative feedback (Alicke \& Sedikides, 2009), we expected (Hypothesis 3 ) that willingness to compromise, which indicates lower defending behaviour, would be associated with perceiving more goal-performance discrepancy (i.e., more openness to change due to perceiving barriers or, in other words, less defensiveness). 
Additionally, as the aim of utilising defending behaviours is to protect against and/or alleviate goal-performance discrepancies, we expected (Hypothesis 4) that defending behaviours (i.e., willingness to compromise) would operate as a mediator between vocational identity and career goal-performance discrepancy (i.e., stronger identity $\rightarrow$ less willingness (i.e., less defending) $\rightarrow$ lower perceived discrepancy). This is consistent with Anderson and Mounts (2012), who recommended that defending behaviours be examined as process variables, rather than simply being viewed as outcomes.

\section{Career Calling}

When young people settle on a career goal "that is meaningful to them and involves personally significant activities" (Praskova, Creed, \& Hood, 2015a, p. 86), they can be said to have developed a career calling. A career calling reflects goal importance in self-regulatory models (e.g., Praskova et al., 2015b), and delineates, for example how much time and energy will be expended on a goal, the extent to which the individual will strive to achieve it, and how readily they will be distracted from it (i.e., willing to compromise on achieving it). From this perspective, a career calling not only defines a particular occupational direction, but also drives the individual's career-related behaviours and affect.

Consistent with this, research has found a positive relationship between career calling and a range of healthy behaviours and affective states (Duffy \& Dik, 2013). Additional to this, when individuals express important goals, they tend to express greater confidence about achieving these goals and strive more to achieve them (Locke \& Latham, 2013). For example, the performance of overqualified employees was found to be stronger when their career calling was higher (Lobene \& Meade, 2013), the relationship between career exploration and planning and perceived employability in young adults was stronger when calling was higher (Praskova et al., 2015b), and, again with young adults, academic stress was related to less burnout in those with a higher calling (Creed, Rogers, Praskova, \& Searle, 
2014). Based on this, we expected that willingness to compromise would be lower when goal importance (i.e., career calling) was higher, no matter what level of vocational identity. Thus, Hypothesis 5 was that career calling would strengthen (i.e., enhance; Jose, 2013) the negative relationship between vocational identity and willingness to compromise.

Additionally, career goal-performance discrepancy should be lower when career calling is higher, as individuals will work harder to protect and defend more important goals (Lord et al., 2010). Thus, we also expected (Hypothesis 6) that career calling would moderate the mediated relationship between vocational identity and career goal-performance discrepancy (via willingness to compromise). To this end, we tested the extent to which this mediated relationship was conditional upon the level of career calling, anticipating that career calling would strengthen (i.e., enhance) the negative relationship between vocational identity and career goal-performance discrepancy.

As young people are constantly monitoring and managing career goal-performance discrepancies (Matschke et al., 2012), this study was designed to shed light on (a) the relationship between vocational identity and career goal-performance discrepancy (Hypothesis 1), (b) the process role that compromise plays in this relationship (Hypotheses 2, 3, and 4), and (c) whether career calling affects young people's use of compromise to manage career goal-importance discrepancies (Hypotheses 5 and 6). Understanding the processes by which vocational identity is related to career goal-performance discrepancy can contribute to vocational identity theory (Holland, Daiger et al., 1980; Skorikov \& Vondracek, 2007, 2011) and inform career development interventions.

\section{Method}

\section{Participants}

Participants were 286 university-enrolled, young adults $(69 \%$ female, mean age $=20.5$ years, $S D=3.2)$. Of these, $61(21 \%)$ reported that their average final high school grade was 
very high achievement, 172 (60\%) reported high achievement, and 53 (19\%) reported satisfactory achievement. For SES, 128 (45\%) indicated living comfortably on present income, 112 (39\%) were managing, and 46 (16\%), were finding it difficult (European Social Survey, 2010). As is typical of Australian universities in general, there is approximately $89 \%$ domestic Australian (largely Caucasian) students at the participating university. All data were collected during the first semester of the students' first year at university and drawn from a potential pool of approximately 460 students (i.e., participant rate $\sim 62 \%$ ).

\section{Measures}

Vocational identity. Vocational identity was assessed using the brief 10 -item version (Hirschi \& Herrmann, 2013) of the My Vocational Situation Inventory (Holland, Daiger, et al., 1980), which assesses the strength and stability of vocational identity (sample item: "I am confused about the whole problem of deciding on a career"; response options $1=$ not true to $5=$ true). All items were coded and totalled so that higher scores represented a stronger vocational identity. Sound previous reliability has been reported $(\alpha=.83)$, and validity has been supported by finding expected correlations with other measures of self-appraisal such as self-efficacy and locus of control (Hirschi \& Herrmann, 2013). Alpha in current study $=.91$.

Willingness/unwillingnes to compromise. We used the 9-item Willingness to Compromise Scale (Wee, 2013), which taps respondents' manner for dealing with uncertainties (e.g., "I stick with my career goals, even when others might think that the goal is not very feasible"; response options $1=$ strongly disagree to $5=$ strongly agree). We coded all items so that higher total scores represented a greater willingness to compromise. Wee (2013) reported an alpha of .77, and supported construct validity by finding positive associations between the scale and career adaptability. Alpha in our study was .76 .

Career goal-performance discrepancy. We used the 12-item Career Goal Discrepancy Scale (Creed \& Hood, 2015), which assesses the perceived gap between current and future 
occupational self/situation (i.e., assesses gap in progress being made towards achieving career-related goals). A sample item is "My performance so far will not get me the career I want" (response options $1=$ strongly disagree to $6=$ strongly agree). Higher scores indicated greater perceived discrepancy. Creed, Wamelink, and $\mathrm{Hu}$ (2015) reported an alpha of .96 with a sample of young adults and, in support of validity, found discrepancy to be related positively to negative feedback from others and to career distress. Alpha in the current study was also 96 .

Career calling. This was measured using the 15-item Career Calling Scale (Praskova et al., 2015c), which was devised specifically for use with young adults (e.g., "I have chosen a career path that will give a real purpose to my life"; response options $1=$ strongly disagree to 6 strongly agree). Higher scores represent higher levels of calling. The scale has been found to have a good internal reliability $(\alpha=.88)$, and, in support of validity, to be associated with life satisfaction and other measures of calling (Praskova et al., 2015c). Alpha with the current sample was .89 .

\section{Procedure}

Participants were contacted via their course website and invited to participate in the study. Volunteers were directed to an online, anonymous questionnaire, and, on completing the questionnaire, were eligible to have their name placed in a draw to win a $\$ 50$ voucher. The study was conducted with the approval of the authors' university ethics committee.

\section{Results}

\section{Testing Mediation}

First, we used latent variable analysis (AMOS V22) to assess if willingness to compromise mediated the relationship between vocational identity and career goalperformance discrepancy. We created three multi-item parcels (Landis, Beal, \& Tesluk, 2000) to represent each latent variable. This process means that fewer, more stable, parameter 
estimates are generated, the reliability of measures is increased, there is less likelihood of violating assumptions of normality, and a more simplified model interpretation is needed (Hau \& Marsh, 2004). Parcels were created by subjecting each scale to an exploratory factor analysis, rank ordering the items according to their factor loadings, and then allocating a mixture of high and low loading items to each parcel (Little, Cunningham, Shahar, \& Widaman 2002).

We assessed these variables in a measurement model, and then tested for mediation using two structural models: the first one tested the direct relationships only (i.e., paths from vocational identity and willingness to compromise to career goal-performance discrepancy); the second tested both the direct and indirect effects together (i.e., paths from vocational identity to willingness to compromise and career goal-performance discrepancy, and a path from willingness to compromise to career goal-performance discrepancy). Using the AMOS bootstrapping procedure (1000 samples), we generated standard errors and $95 \%$ biascorrected confidence intervals (CIs). Mediation can be considered to exist when the CIs for the indirect effect do not include zero (Preacher \& Hayes, 2008). Model fit was evaluated using $\chi^{2}$ (with 9 observed variables and a sample size $>250$, a non-significant $\chi^{2}$ is expected), the standardised chi-square $\left(\chi^{2} / d f<3.0\right.$ indicates a good fit $)$, the Comparative Fit Index (CFI > .95), and the Root Mean Square Error of Approximation (RMSEA < .07; Hair, Black, Babin, \& Anderson, 2010). Additionally, we controlled for age, gender, SES, and educational achievement, which had weak, but significant, bivariate correlations $(<.22)$ with the outcome variables.

The measurement model was a good fit to the data: $\chi^{2}(24)=44.59, p=.007, \chi^{2} / d f=1.86$, $\mathrm{CFI}=.99$, RMSEA $=.06$. Factor loadings ranged from .62 to $.98($ all $p<.001)$, and correlations among the latent variables (range $\mid .54$ to $.61 \mid$; all $p<.001$ ) mirrored the bivariate correlations (range $\mid .46$ to $.51 \mid$; all $p<.001$ ); see Table 1 . 
The fit statistics for the direct effects model (13 observed variables and sample size > 250) was also good, $\chi^{2}(53)=113.71, p<.001, \chi^{2} / d f=2.15, \mathrm{CFI}=.97, \mathrm{RMSEA}=.06$. The paths from vocational identity to goal-performance discrepancy $(\beta=-.52, p<.001)$ and from vocational identity to willingness to compromise $(\beta=-.62, p<.001)$ were both significant. Educational achievement $(\beta=.13, p=.013)$ was also related to discrepancy.

In the indirect effects model, $\chi^{2}(52)=87.94, p=.001, \chi^{2} / d f=1.69, \mathrm{CFI}=.98, \mathrm{RMSEA}=$ .05 , the paths from vocational identity to goal-performance discrepancy $(\beta=-.27, p<.001)$, vocational identity to willingness to compromise $(\beta=-.61, p<.001)$, and willingness to compromise to goal-performance discrepancy $(\beta=.39, p<.001)$ were significant, as was the path from education $(\beta=.12, p=.014)$ to discrepancy. The CIs for the indirect effects from vocational identity to discrepancy via willingness to compromise $\left(\mathrm{CI}_{95}=-.44\right.$ to -.16$)$ did not contain zero, indicating that willingness to compromise mediated between vocational identity and discrepancy (as the direct path remained significant in the presence of the mediator, the mediation was partial). See Figure 2. Overall, the predictors accounted for $37 \%$ of the variance in willingness to compromise and $41 \%$ in discrepancy. The standardised indirect effect of identity on discrepancy was $24 \%$ (Shrout \& Bolger, 2002).

\section{Moderated Mediation}

We used the Process (Model 7) bootstrapping procedure (Hayes, 2013) to test the hypothesised moderated-mediation reported in Figure 1. We assessed (a) if career calling moderated the relationship between vocational identity and willingness to compromise, and (b) if career calling moderated the indirect relationship between vocational identity and career goal-performance discrepancy.

First, both vocational identity and career calling were independently related to willingness to compromise, as was the interaction term vocational identity $\mathrm{x}$ career calling (Table 2, Model 1). Simple slope tests (Aiken \& West, 1991) showed that career calling 
strengthened the relationship between vocational identity and willingness to compromise, with willingness to compromise reducing disproportionately more as vocational identity got higher for the high career calling group $(+1 S D)$ compared to the low career calling group ($1 S D)$. See Figure 3.

Second, moderated mediation (i.e., when the indirect relationship between vocational identity and career goal-performance discrepancy via willingness to compromise is influenced by the level of career calling) is indicated when the linear correlation between the specific indirect effect and the moderator (i.e., the index of moderated mediation) differs from zero (Hayes, 2015). We used the bootstrapping procedure to calculate $95 \%$ bias-corrected confidence intervals (CIs) for the index of moderated mediation, which is significant when the CIs do not include zero, and then inspected the size and direction of the index to facilitate interpretation. The CIs for the index of moderated mediation did not contain zero (Table 2, Model 2), which indicated that the indirect relationship between vocational identity and career goal-performance discrepancy via willingness to compromise was moderated by career calling. See Figure 4.

\section{Discussion}

We tested the relationship between vocational identity and career goal-performance discrepancy and assessed the process roles of willingness to compromise (i.e., defending behaviour) as mediator and career calling (i.e., goal importance) as moderator in this relationship. Developing a healthy and robust vocational identity is an essential task for young people as they prepare themselves for challenging $21^{\text {st }}$ Century labour markets (LaPointe, 2010). However, despite this, there is still no consensus as to how identity develops (Vignoles, Schwartz, \& Luyckx, 2011), and few studies have examined potential underlying processes related to the development of vocational identity (Skorikov \& Vondracek, 2007, 2011). 
First, supporting Hypothesis 1, we confirmed that vocational identity was related negatively to career goal-performance discrepancy (i.e., young adults with a stronger sense of vocational identity reported perceiving fewer career-related discrepancies). This finding is consistent with previous research, which has shown that young adults with a less well-defined vocational identity perceive more career-related obstacles and barriers (Gushue et al., 2006), report receiving more negative career-related feedback (Dobrow \& Tosti-Kharas, 2012), and report higher levels of distress (Creed \& Hennessey, 2016); whereas young people with more well-developed vocational identities are better able to deal with internal and external barriers, remain more connected to their vocational future (Diemer \& Blustein, 2007), and seek less help with career and personal matters (Holland, Daiger et al., 1980). Our study provides evidence for a theoretical connection between vocational identity and career-related goalperformance discrepancies, which is consistent with the goal setting and self-regulatory approach (cf. Bandura, 1991, 2001; Carver \& Scheier, 1990; Locke \& Latham, 2013).

The negative relationship between vocational identity and goal-performance discrepancy is also consistent with self-verification processes, which acknowledge that individuals have a basic need to construct their social environment so that the feedback they receive is congruent with their own self-evaluations (Swann, 1987). This means that individuals will work to avoid or downplay negative feedback and seek feedback consistent with the way they view themselves. Dobrow and Tosti-Kharas (2012), for example, found that young people with a higher career calling were more likely to ignore negative career advice than those with a lower calling, and Hallier and Summers (2011) showed that final-year HRM students adopted a range of protective mechanisms to maintain their occupational identity, such as ignoring negative feedback and advice. Our results, thus, suggest that those with a stronger vocational identity implement processes that aim to reduce perceptions that there are discrepancies between their vocational goals/standards and their vocational progress and/or achievement. 
We assessed willingness to compromise, which, as a defending or self-protecting behaviour, operates to preserve identity homeostasis (Alicke \& Sedikides, 2009), which young adults might use to reduce the number/severity of discrepancies, and thereby protect themselves from discomfort and the need to re-evaluate goals/standards or change their behaviours. Supporting Hypothesis 2, we found a negative relationship between vocational identity and willingness to compromise (i.e., those with a stronger vocational identity reported less willingness to compromise), and supporting Hypothesis 3, willingness to compromise was associated positively with discrepancy (i.e., those with a higher willing to compromise reported perceiving more discrepancies). Finally, and partly supporting Hypothesis 4, willingness to compromise partially mediated between vocational identity and discrepancy. These results are consistent with the notion that when vocational identity is higher, more effort is applied to defending the current status, which, in turn, reduces the perceptions of discrepancies between self-set goals or standards and environmental feedback (cf. Gregg et al., 2011). The results are also consistent with goal setting and self-regulatory theories (e.g., Bandura, 1991, 2001), and specifically identity control theory (Burke, 1991), which has been proposed to account for vocational identity development (Anderson \& Mounts, 2012).

Finally, we also tested whether career calling affected this process by strengthening the negative relationship between vocational identity and willingness to compromise, and strengthening the negative relationship between vocational identity and goal-performance discrepancy. Both of these propositions were supported. The results suggest that when young people see their career direction as important, they are likely to ignore or downplay negative feedback, as this is inconsistent with their general career direction and likely to lead them to feel uncomfortable or distressed (Dobrow \& Tosti-Kharas, 2012; Swann, Pelham, \& Krull, 1989). Thus, career calling, which reflects career goal importance (Praskova et al., 2015b), is 
likely to increase the use of defending behaviours such as being unwilling to compromise, and, by extension, reduce their perception of discrepancies. This interpretation is consistent with self-verification theory (i.e., people seek to preserve strongly held self-conceptions; Swann, 1987; Swann et al., 1989), goal-setting and self-regulatory processes (e.g., Bandura, 1991, 2001), and the SOC model (i.e., taking compensatory actions to manage threat to the self; Baltes, 1997).

\section{Implications for Practice}

There are practical implications from this study. First, developing a healthy and robust vocational identity is highly desirable (Murphy et al., 2010; Porfeli et al., 2011). As we have shown, this is associated with perceiving fewer discrepancies between desired direction/achievement and self-set goals and standards. Perceptions of fewer discrepancies can be accounted for, at least in part, by more defending behaviour, that is, by less willingness to compromise; especially by those who perceive their career goals as important. Self-defending strategies and behaviours are pervasive in human functioning (Gregg et al., 2011); however, for those who are strongly committed to a particular self-conception, and especially those who are firm about their career direction, there is the potential that they might ignore or downplay information that could assist with their career direction (London \& Smither, 2002), implying that counsellors need to be cautious when young people express overly strong career goals.

Second, finding support for an underlying mechanism for vocational identity development should encourage practitioners and policy makers to devise interventions and implement strategies that are consistent with such an approach. Young people develop standards for themselves and set career and other life goals. These standards and goals are influenced by feedback from the environment and self-reflection, and, as has been shown in the current study, are affected by self-protective mechanisms. In this context, interventions to foster 
vocational identity development should include aspects that focus on managing feedback, especially negative feedback, and strategies that address personal biases and defending.

\section{Limitations \& Future Research}

While we tested a process model, our study was cross-sectional; thus, we were not able to make strong statements about causality. We drew on goal-setting and self-regulatory models for the direction of our relationships, but these need to be tested in future research by collecting data over multiple times. This study should give confidence to future researchers to do this. Also, we used only one measure of defending behaviours (i.e., willingness to compromise), and others need to be assessed for their role. Last, we were not able to differentiate between self-protective and self-enhancing behaviours (cf. Alicke \& Sedikides, 2009), and future studies could do this. A better understanding of how these defending and enhancing behaviours affect processes around vocational identity development will allow more useful interventions to be devised for young people as they develop their vocational identity and make the transition to adulthood and the adult labour market.

\section{References}

Aiken, L. S., \& West, S. G. (1991). Multiple regression. Newbury Park, CA: Sage.

Alicke, M. D., \& Sedikides, C. (2009). Self-enhancement and self-protection: What they are and what they do? European Review of Social Psychology, 20, 1-48. doi:10.1080/10463280802613866

Anderson, K. L., \& Mounts, N. S. (2012). Searching for the self. The Journal of Genetic Psychology, 173, 90-111. doi:10.1080/00221325.2011.573027

Baltes, P. B. (1997). On the incomplete architecture of human ontogeny: Selection, optimization, and compensation as foundation of developmental theory. American Psychologist, 52, 366-380. doi:10.1037/0003-066X.52.4.366 
Bandura, A. (1991). Social cognitive theory of self-regulation. Organizational Behavior and Human Decision Processes, 50, 248-287. doi:10.1016/0749-5978(91)90022-L

Bandura, A. (2001). Social cognitive theory: An agentic perspective. Annual Review of Psychology, 52, 1-26. doi:10.1146/annurev.psych.52.1.1

Betz, N. E., Hammond, M. S., \& Multon, K. D. (2005). Reliability and validity of five-level response continua for the Career Decision Self-Efficacy Scale. Journal of Career Assessment, 13, 131-149. doi:10.1177/1069072704273123

Burke P. J. (1991). Identity processes and social stress. American Sociological Review, 836849. doi:10.2307/2096259

Carver, C. S., \& Scheier, M. (1990). Principles of self-regulation: Action and emotion. New York, NY: Guilford Press.

Caudroit, J., Stephan, Y., Brewer, B. W., \& Le Scanff, C. (2010). Contextual and individual predictors of psychological disengagement from sport during a competitive event. Journal of Applied Social Psychology, 40, 1999-2018. doi:10.1111/j.1559-1816.2010.00648.x

Cramer, P. (2000). Defense mechanisms in psychology today: Further processes for adaptation. American Psychologist, 55, 637-646. doi:10.1037/0003-066X.55.6.637

Creed, P. A., \& Gagliardi, R. (2014). Career compromise, career distress, and perceptions of employability: The moderating roles of social capital and core self-evaluations. Journal of Career Assessment, 23, 20-34. doi:10.1177/1069072714523082

Creed, P. A., \& Hennessey, D. (2016). Goal orientation and career identity. Career Development Quarterly.

Creed, P. A., \& Hood, M. (2015). The development and initial validation of a scale to assess career goal discrepancies. Journal of Career Assessment, 23, 308-317. doi:10.1177/1069072714535175. 
Creed, P. A., Rogers, M. E., Praskova, A., \& Searle, J. (2014). Career calling as a personal resource moderator between environmental demands and burnout in Australian junior doctors. Journal of Career Development, 41(6), 547-561.DOI: $10.1177 / 0894845313520493$

Creed, P. A., Wamelink, T., \& Hu, S. (2015). Antecedents and consequences to perceived career goal-progress discrepancies. Journal of Vocational Behavior, 87, 43-53. doi:10.1016/j.jvb.2014.12.001

Diemer, M. A., \& Blustein, D. L. (2007). Vocational hope and vocational identity: Urban adolescents' career development. Journal of Career Assessment, 15, 98-118. doi:10.1177/1069072706294528

Dobrow, S. R., \& Tosti-Kharas, J. (2012). Listen to your heart? Calling and receptivity to career advice. Journal of Career Assessment, 20, 264-280. doi: $10.1177 / 1069072711434412$

Donovan, J. J., \& Williams, K. J. (2003). Missing the mark: Effects of time and causal attributions on goal revision in response to goal-performance discrepancies. Journal of Applied Psychology, 88, 379. doi:10.1037/0021-9010.88.3.379

Downing, H. M., \& Nauta, M. M. (2010). Separation-individuation, exploration, and identity diffusion as mediators of the relationship between attachment and career indecision. Journal of Career Development, 36, 207-227. doi:10.1177/0894845309345848

Duffy, R. D., \& Dik, B. J. (2013). Research on calling: What have we learned and where are we going? Journal of Vocational Behavior, 83, 428-436. doi:10.1016/j.jvb.2013.06.006 European Social Survey (2010). ESS Round 5 Source Questionnaire. London: Centre for Comparative Social Surveys, City University London. 
Gottfredson, L. S. (2005). Applying Gottfredson's theory of circumscription and compromise in career guidance and counselling (71-100). In S. D. Brown \& R. W. Lent (Eds.), Career development and counselling (pp. 101-127). Hoboken, NJ: John Wiley \& Sons.

Gregg, A. P., Sedikides, C., \& Gebauer, J. E. (2011). Dynamics of identity: Between selfenhancement and self-assessment. In S. J. Schwartz, K. Luyckx, \& V. L. Vignoles (Eds.), Handbook of identity theory and research (pp. 305-327). New York, NY: Springer.

Green, J. D., Sedikides, C., Pinter, B., \& Van Tongeren, D. R. (2009). Two sides to selfprotection: Self-improvement strivings and feedback from close relationships eliminate mnemic neglect. Self and Identity, 8, 233-250. doi.10.1080/15298860802505145

Guichard, J., Pouyaud, J., De Calan, C., \& Dumora, B. (2012). Identity construction and career development interventions with emerging adults. Journal of Vocational Behavior, 81, 52-58. doi:10.1016/j.jvb.2012.04.004

Gushue, G. V., Clarke, C. P., Pantzer, K. M., \& Scanlan, K. R. (2006). Self-efficacy, perceptions of barriers, vocational identity, and the career exploration behavior of Latino/a high school students. The Career Development Quarterly, 54, 307-317. doi:10.1002/j.2161-0045.2006.tb00196.x

Hair, J. F., Black, W. C., Babin, B. J., \& Anderson, R. E. (2010). Multivariate data analysis. Upper Saddle River, NJ: Prentice Hall.

Hallier, J., \& Summers, J. (2011). Dilemmas and outcomes of professional identity construction among students of human resource management. Human Resource Management Journal, 21, 204-219. doi:10.1111/j.1748-8583.2010.00132.x

Hayes, A. F. (2013). Introduction to mediation, moderation, and conditional process analysis: A regression-based approach. New York, NY: Guilford Press. 
Heppner, W. L., \& Kernis, M. H. (2011). High self-esteem: Multiple forms and their outcomes. In S. J. Schwartz, K. Luyckx, \& V. L. Vignoles (Eds.), Handbook of identity theory and research (pp. 329-355). New York, NY: Springer.

Hirschi, A. (2011). Vocational identity trajectories: Differences in personality and development of well-being. European Journal of Personality, 26, 2-12. doi:10.1002/per.812

Hirschi, A. (2012). Vocational identity trajectories: Differences in personality and development of well-being. European Journal of Personality, 26, 2-12. doi:10.1002/per.812

Hirschi, A., \& Herrmann, A. (2013). Difficulties in career decision-making among Swiss adolescents: Assessment with the German My Vocational Situation Scale. Swiss Journal of Psychology, 72, 33-42. doi:10.1024/1421-0185/a000097

Hirschi, A., Herrmann, A., \& Keller, A. C. (2015). Career adaptivity, adaptability, and adapting: A conceptual and empirical investigation. Journal of Vocational Behavior, 87, 1-10. doi:10.1016/j.jvb.2014.11.008

Holland, J. L., Daiger, D. C., \& Power, P. G. (1980). My Vocational Situation: Manual. Palo Alto, CA: Consulting Psychologist Press.

Holland, J. J., Gottfredson, D. C., \& Power, P. G. (1980). Some diagnostic scales for research in decision making and personality: Identity, information, and barriers. Journal of Personality and Social Psychology, 39, 1191-1200. doi:10.1037/h0077731

Holland, J. L., Magoon, T. M., \& Spokane, A. R. (1981). Counseling psychology: Career interventions, research, and theory. Annual Review of Psychology, 32, 279-305. doi:10.1146/annurev.ps.32.020181.001431 
Hu, S., Hood, M., \& Creed, P. A. (2016). Career goal importance as a moderator in the relationship between career feedback and career-related stress. Journal of Career Development. doi:10.1177/0894845316667847

Iyengar, S. S., Wells, R. E., \& Schwartz, B. (2006). Doing better but feeling worse looking for the "best" job undermines satisfaction. Psychological Science, 17, 143-150. doi:10.1111/j.1467-9280.2006.01677.x

Jose, P. E. (2013). Doing statistical mediation and moderation. New York, NY: Guilford Press.

Kerpelman, J. L., Pittman, J. F., \& Lamke, L. K. (1997). Toward a microprocess perspective on young adult identity development: An identity control theory approach. Journal of Adolescent Research, 12, 325-246. doi:10.1177/0743554897123002

Landis, R. S., Beal, D. J., \& Tesluk, P. E. (2000). A comparison of approaches to forming composite measures in structural equation models. Organizational Research Methods, 3, 186-207. doi:10.1177/109442810032003

LaPointe, K. (2010). Narrating career, positioning identity: Career identity as a narrative practice. Journal of Vocational Behavior, 77, 1-9. doi:10.1016/j.jvb.2010.04.003

Lent, R. W. (2005). A social cognitive view of career development and counselling. In S. D. Brown \& R. W. Lent (Eds.), Career development and counselling (pp. 101-127). Hoboken, NJ: John Wiley \& Sons.

Little, T. D., Cunningham, W. A., Shahar, G., \& Widaman, K. F. (2002). To parcel or not to parcel: Exploring the question, weighing the merits. Structural Equation Modeling, 9, 151-173. doi:10.1207/S15328007SEM0902_1

Lobene, E. V., \& Meade, A. W. (2013). The effects of career calling and perceived overqualification on work outcomes for primary and secondary school teachers. Journal of Career Development, 40, 508-530. doi:10.1177/0894845313495512 
Locke, E. A., \& Latham, G. P. (2013). Goal setting theory: The current state. In E. A. Locke \& G. P. Latham, New developments in goal setting and task performance (pp. 623-630). New York, NY: Routledge.

London, M., \& Smither, J. W. (2002). Feedback orientation, feedback culture, and the longitudinal performance management process. Human Resource Management Review, 12, 81-100. doi: 10.1016/S1053-4822(01)00043-2

Lord, R. G., Diefendorff, J. M., Schmidt, A. M., \& Hall, R. J. (2010). Self-regulation at work. Annual Review of Psychology, 61, 543-568. doi:10.1146/annurev.psych.093008.100314

Matschke, C., Fehr, J., \& Sassenberg, K. (2012). When does goal discrepancy induce compensatory effort? An application of self-completion theory to social issues. Social and Personality Psychology Compass, 6, 536-550. doi:10.1111/j.1751-9004.2012.00444.x

Murphy, K. A., Blustein, D. L., Bohlig, A. J., \& Platt, M. G. (2010). The college-to-career transition: An exploration of emerging adulthood. Journal of Counseling and Development, 88, 174-181. doi:10.1002/j.1556-6678.2010.tb00006.x

Porfeli, E. J., Lee, B., Vondracek, F. W., \& Weigold, I. K. (2011). A multi-dimensional measure of vocational identity status. Journal of Adolescence, 34, 853-871. doi:10.1016/j.adolescence.2011.02.001

Praskova, A., Creed, P. A., \& Hood, M. (2015a). Self-regulatory processes mediating between career calling and perceived employability and life satisfaction in emerging adults. Journal of Career Development, 42, 86-101.doi:10.1177/0894845314541517

Praskova, A., Creed, P. A., \& Hood, M. (2015b). Career identity and the complex mediating relationships between career preparatory actions and career progress markers. Journal of Vocational Behavior, 87, 145-153. doi:10.1016/j.jvb.2015.01.001 
Praskova, A., Creed, P. A., \& Hood, M. (2015c). The development and initial validation of a career calling scale for emerging adults. Journal of Career Assessment, 23, 91-106. doi:10.1177/1069072714523089

Preacher, K. J., \& Hayes, A. F. (2008). Asymptotic and resampling strategies for assessing and comparing indirect effects in multiple mediator models. Behavior Research Methods, 40, 879-891. doi:10.3758/BRM.40.3.879

Savickas, M. L. (2005). The theory and practice of career construction. In S. D. Brown \& R. W. Lent (Eds.), Career development and counselling (pp. 42-70). Hoboken, NJ: John Wiley.

Schwartz, B., Ward, A., Monterosso, J., Lyubomirsky, S., White, K., \& Lehman, D. R. (2002). Maximizing versus satisficing: Happiness is a matter of choice. Journal of Personality and Social Psychology, 83, 1178-1197. doi:10.1037/0022-3514.83

Shin, Y. J., \& Kelly, K. R. (2013). Cross-cultural comparison of the effects of optimism, intrinsic motivation, and family relations on vocational identity. The Career Development Quarterly, 61, 141-160. doi:10.1002/J.2161-0045.2013.00043.X

Shrout, P. E., \& Bolger, N. (2002). Mediation in experimental and nonexperimental studies: New procedures and recommendations. Psychological Methods, 7, 422-445. doi:10.1037//1082-989X.7.4.422

Skorikov, V. B., \& Vondracek, F. W. (2007). Vocational identity. In V. B. Skorikov \& W. Patton (Eds.), Career development in childhood and adolescence (pp. 143-168). Rotterdam, NL: Sense.

Skorikov, V. B., \& Vondracek, F. W. (2011). Occupational identity. InS. J. Schwartz, K. Luyckx, \& V. L. Vignoles (Eds.), Handbook of identity theory and research (pp. 693714). New York, NY: Springer. 
Sparks, E. A., Ehrlinger, J., \& Eibach, R. P. (2012). Failing to commit. Personality and Individual Differences, 52, 72-77. doi:10.1016/j.paid.2011.09.002

Swann, W. B., Jr. 1987. Identity negotiation: Where two roads meet. Journal of Personality and Social Psychology, 53, 1038-1051. doi:10.1037/0022-3514.53.6.1038

Swann Jr, W. B., Pelham, B. W., \& Krull, D. S. (1989). Agreeable fancy or disagreeable truth? Reconciling self-enhancement and self-verification. Journal of Personality and Social Psychology, 57, 782-791. doi:10.1037/0022-3514.57.5.782

Sweeney, M. L., \& Schill, T. R. (1998). The association between self-defeating personality characteristics, career indecision, and vocational identity. Journal of Career Assessment, 6, 69-81. doi:10.1177/106907279800600105

Taylor, S. E., \& Brown, J. D. (1988). Illusion and well-being. Psychological Bulletin, 103, 193-210. doi:10.1037/0033-2909.103.2.193

Tsaousides, T., \& Jome, L. (2008). Perceived career compromise, affect and work-related satisfaction in college students. Journal of Vocational Behavior, 73, 185-194. doi:10.1016/j.jvb.2008.04.003

Vignoles, V. L., Schwartz, S. J., \& Luyckx, K. (2011). Towards an integrative view of identity. In S. J. Schwartz, K. Luyckx, \& V. L. Vignoles (Eds.), Handbook of identity theory and research (pp. 1-27). New York, NY: Springer.

Wang, C., \& Mukhopadhyay, A. (2012). The dynamics of goal revision. Journal of Consumer Research, 38, 815-832. doi:10.1086/660853

Wee, S. (2013). Development and initial validation of the Willingness to Compromise Scale. Journal of Career Assessment, 21, 487-501. doi:10.1177/1069072712475281 
Table 1

Summary Data $(N=260)$

\begin{tabular}{lcrrrrr}
\hline Variables & $M$ & $S D$ & 1 & 2 & 3 & 4 \\
\hline 1. Vocational identity & 36.81 & 9.16 & - & -.49 & -.51 & .57 \\
2. Willingness to compromise & 22.91 & 4.62 & -.61 & - & .46 & -.65 \\
3. Goal-performance discrepancy & 32.62 & 13.50 & -.54 & .57 & - & -.45 \\
4. Career calling & 65.77 & 9.96 & - & - & - & -
\end{tabular}

Note: Bivariate correlations are reported above the diagonal, correlations among latent variables are below; all correlations $p<.001$. 
Table 2

Summary Data for Moderated-Mediation Models $(N=260)$

\begin{tabular}{|c|c|}
\hline Models & Summary Data \\
\hline \multicolumn{2}{|l|}{ Model 1} \\
\hline Vocational identity $\rightarrow$ Willingness to compromise & $R^{2}=.46, F(7,278)=33.77, p<.001$ \\
\hline Vocational identity (VI) & $-.10 * * *$ \\
\hline Career calling (CC) & $-.26 * * *$ \\
\hline $\mathrm{VI} \times \mathrm{CC}$ & $-.01 *$ \\
\hline \multicolumn{2}{|l|}{ Model 2} \\
\hline Vocational identity $\rightarrow$ Goal-performance discrepancy & $R^{2}=.34 ; F(6,279)=23.84, p<.001$ \\
\hline Vocational identity & $-.50 * * *$ \\
\hline Willingness to compromise & $.81 * * *$ \\
\hline Index of moderated mediation (Indirect effect) & -.01 (CIs: -.009 to -.001$)$ \\
\hline
\end{tabular}

Note: Coefficients are unstandardized. ${ }^{*} p<.05 ; * * * p<.001$. 


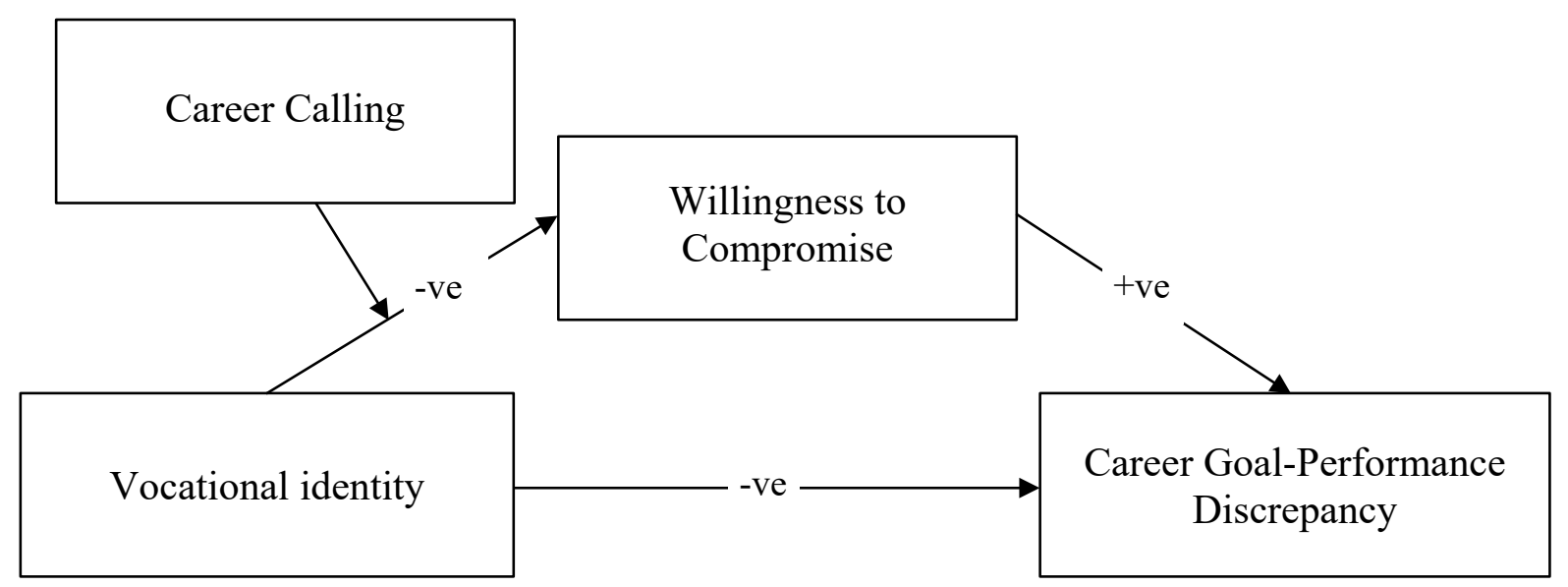

Figure 1. Hypothesized model: The relationship between vocational identity and career goalperformance discrepancy is mediated by willingness to compromise, and the mediated relationship is moderated by career calling. 


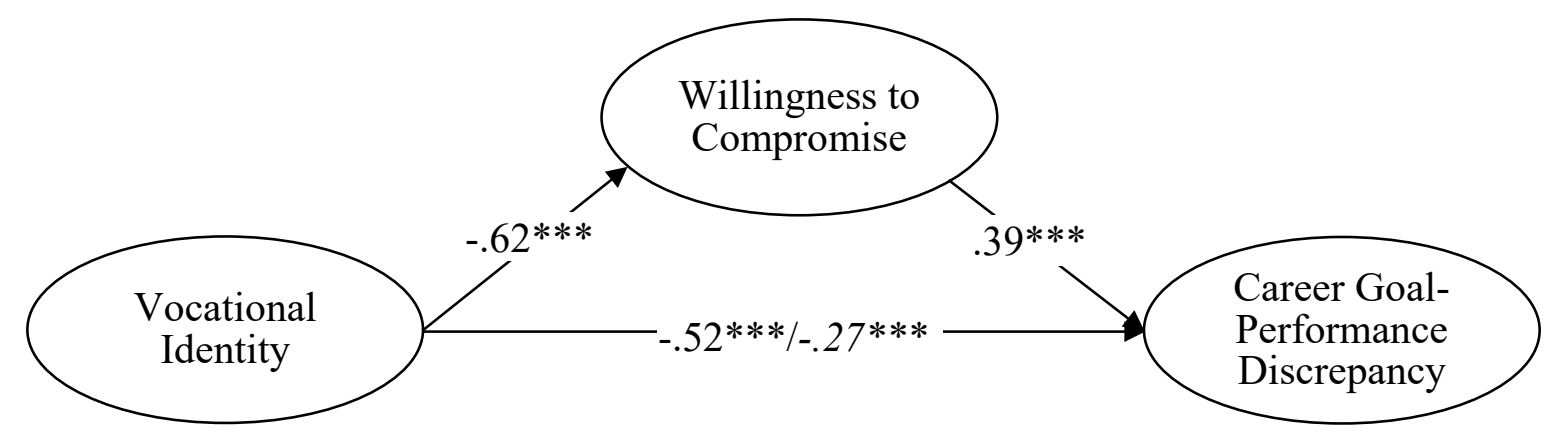

Figure 2. Willingness to compromise partially mediated between vocational identity and career goal-performance discrepancy. Standardised regression weights are reported; those in italics are effects when mediator was present. 


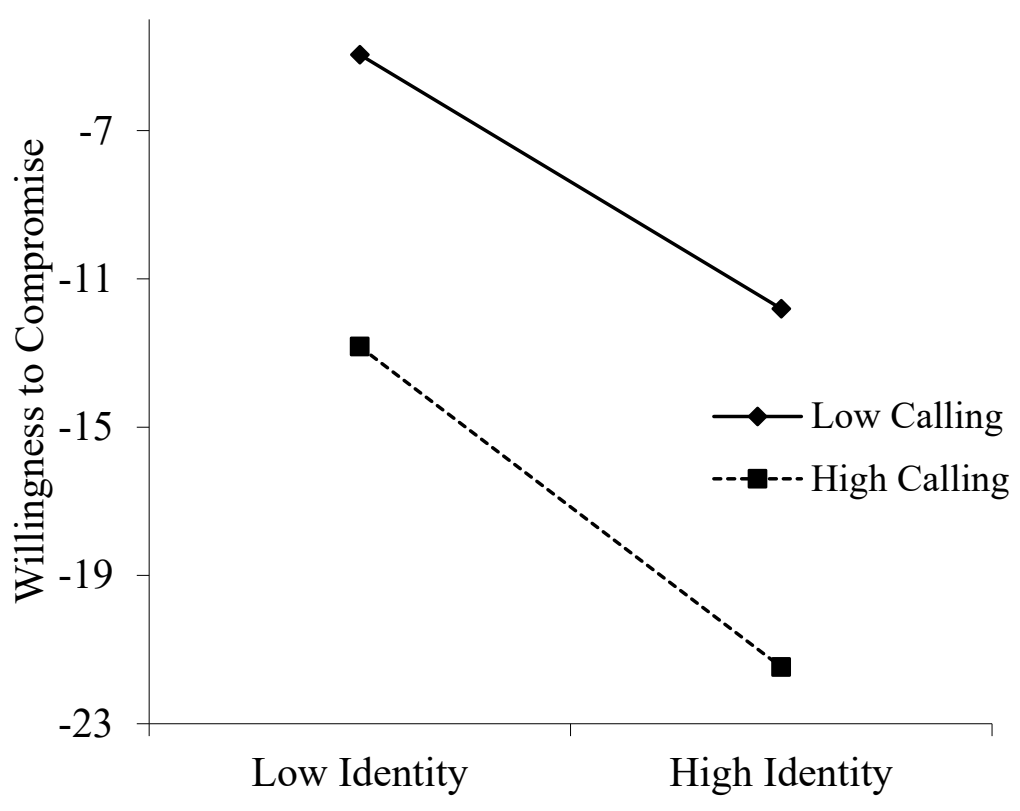

Figure 3. Career calling moderates the relationship between vocational identity and willingness to compromise. 


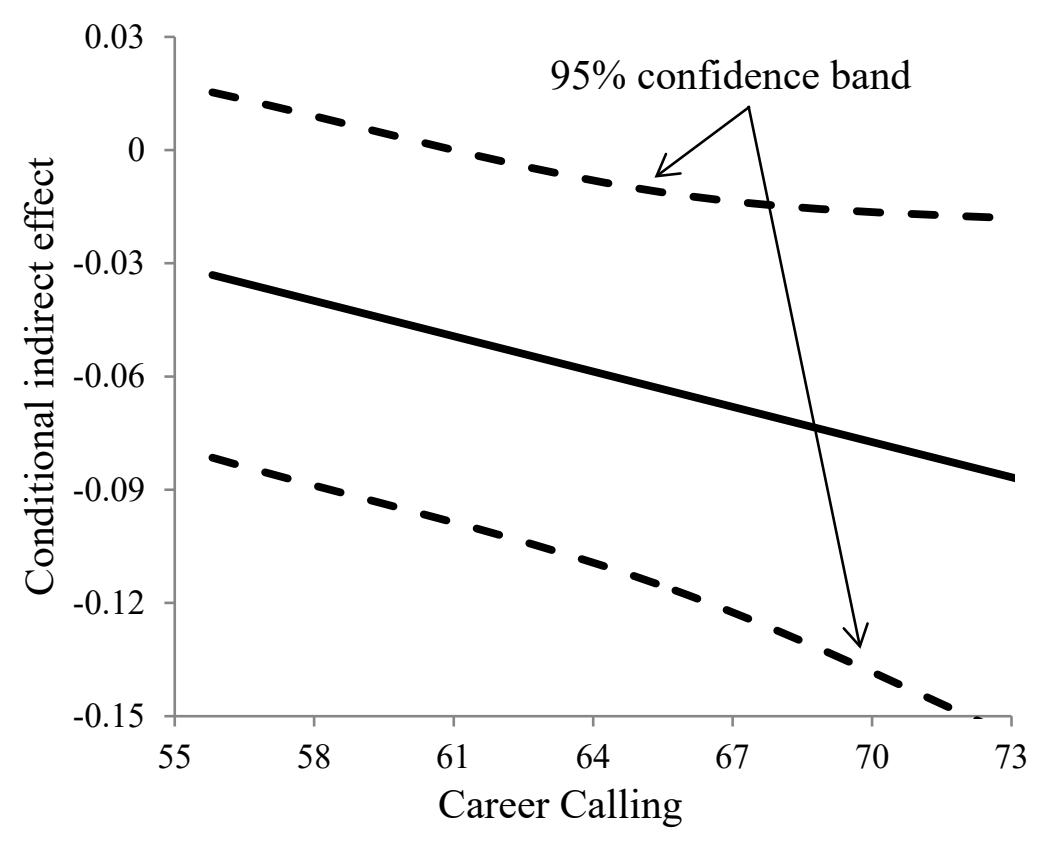

Figure 4. Conditional indirect effect for vocational identity on career goal-performance discrepancy via willingness to compromise and moderated by career calling. 